\title{
Loss of Egr1, a human del5q gene, accelerates BCR-ABL driven chronic myelogenous leukemia
}

\author{
Silvia Maifrede ${ }^{1,3, *}$, Andrew Magimaidas ${ }^{1,2, *}$, Xiaojin Sha ${ }^{1}$, Kaushiki Mukherjee ${ }^{1}$, \\ Dan A. Liebermann ${ }^{1,4}$ and Barbara Hoffman ${ }^{1,4}$ \\ ${ }^{1}$ Fels Institute for Cancer Research and Molecular Biology, Temple University Lewis Katz School of Medicine, Philadelphia, \\ PA, USA \\ ${ }^{2}$ Current address: Department of Systems Pharmacology and Translational Therapeutics, Perelman School of Medicine, \\ University of Pennsylvania \\ ${ }^{3}$ Department of Microbiology and Immunology, Temple University Lewis Katz School of Medicine, Philadelphia, PA, USA \\ ${ }^{4}$ Department of Medical Genetics and Molecular Biochemistry, Temple University Lewis Katz School of Medicine, Philadelphia, \\ PA, USA \\ ${ }^{*}$ Co-first author \\ Correspondence to: Barbara Hoffman, email: hoffman@temple.edu
}

Keywords: Egrl, chronic myelogenous leukemia, stress response protein, tumor suppressor, Leukemic stem cells

Received: May 11,2017 Accepted: August 04, $2017 \quad$ Published: September 01, 2017

Copyright: Maifrede et al. This is an open-access article distributed under the terms of the Creative Commons Attribution License 3.0 (CC BY 3.0), which permits unrestricted use, distribution, and reproduction in any medium, provided the original author and source are credited.

\section{ABSTRACT}

There is substantial evidence that early growth response-1 (Egr1) gene, a zincfinger transcription factor, behaves as a tumor suppressor in leukemia. This includes reports from this laboratory that constitutive Egr1 overrides leukemia conferred by deregulated C-Myc or E2F-1 in the M1 myeloid leukemic cell line by promoting differentiation. To investigate the effect of Egr1 on the initiation and progression of Chronic Myelogenous Leukemia (CML), lethally irradiated syngeneic wild type mice were reconstituted with bone marrow (BM) from either wild type or Egr1 null mice transduced with a 210-kD BCR-ABL-expressing MSCV-retrovirus (bone marrow transplantation \{BMT\}). Loss of Egr1 was observed to accelerate the development of $B C R-A B L$ driven leukemia in recipient mice, resulting in the development of a more aggressive disease, a significantly shortened median survival time, and increased BCR-ABL expressing leukemic stem/progenitor cells (GFP+Lin-cKit+Sca+). Egr1 deficient progenitors expressing BCR-ABL exhibited decreased apoptosis, and increased cell viability and proliferation relative to WT counterparts. Secondary BMT of BCR-ABL BM revealed that loss of Egr1 resulted in enrichment of LSCs, consistent with shorter survival time and more aggressive disease of these mice compared to WT counterparts. Furthermore, serial re-plating colony assays indicated that loss of Egr1 increased self-renewal ability of BCR-ABL expressing BM. These novel findings on the tumor suppressor role of Egr1 in CML provide the impetus to study the effect of altering Egr1 expression in $A M L$, where the overall five year survival rate remains low. The effect of loss of Egr1 in CML could reflect its established functions in normal hematopoiesis, maintaining quiescence of HSCs and driving terminal differentiation to the monocyte/macrophage lineage. Gain of function studies should validate these conclusions and provide further rationale for increased Egr1 as a therapeutic target in AML.

\section{INTRODUCTION}

The early growth response-1 (Egr1) gene, a zinc-finger transcription factor localized to the human chromosome 5 [1], is rapidly stimulated by growth factors, hormones and neurotransmitters [2]. In addition, Egr1 is a myeloid differentiation primary response (MYD) gene, and is a positive regulator of terminal myeloid differentiation that potentiates macrophage differentiation [3-8]. There is substantial evidence that Egr1 behaves 
as a tumor suppressor in leukemia. Deletions in the $5 q$ region, where Egr1 and several other tumor suppressor genes are mapped, is often observed in therapy-related myeloid neoplasms (t-MN) [9], a subset of patients with primary myelodysplastic syndrome (MDS), and about $15 \%$ of patients with acute myeloid leukemia (AML) de novo [10]. Furthermore, it has been demonstrated in mouse models that haplo-insufficiency of Egr1 leads to development of myeloid disorders [11, 27-28]. This laboratory has demonstrated that constitutive Egr1 can override leukemia conferred by deregulated c-Myc or E2F-1 in the M1 myeloid leukemic cell line by promoting differentiation [11-13]. It has also been shown that Ezh2 directly regulates Egr1 in hematopoiesis, and that deletion of Ezh2 and the reactivation of genes repressed by it, including Egr1, converted a high-grade myeloid leukemia to a less aggressive myeloid neoplasia (MPN) $[14,15]$. Another study has demonstrated that Egr1 can also behave as a tumor suppressor in AML1-ETO-positive AML [16]. In addition, Egr1 directly regulates multiple tumor suppressor genes including TGF $\beta 1$, PTEN, p53 and fibronectin [17], some of which have been implicated to regulate CML [18-20]. This large body of evidence consistent with Egr1 behaving as a tumor suppressor in hematopoietic cells, both in vivo \& in vitro and in both humans and mice, led us to ask if Egr1 plays a role in Chronic Myelogenous Leukemia (CML).

CML is a hematological disease originating from a reciprocal chromosomal translocation $\mathrm{t}(9 ; 22)(\mathrm{q} 34 ; \mathrm{q} 11)$ in pluripotent hematopoietic stem cells, generating the Philadelphia chromosome $(\mathrm{Ph})$ [21]. This translocation results in the chimeric $\mathrm{BCR}-\mathrm{ABL}$ oncogene, encoding for a constitutively active protein kinase [22]. CML is typically diagnosed in chronic phase (CP), characterized by elevated levels of granulocytes. If left untreated additional mutations arise that impact on differentiation, DNA repair and telomere maintenance, as well as loss of tumor suppressor genes [23], with concomitant disease progression. There is transition to accelerated phase (AP) and ultimately to blast crisis (BC) associated with rapid expansion of blast cells [23-24].

In this study we used a mouse model of bone marrow transplantation (BMT) for BCR-ABL driven leukemia and observed that loss of Egrl in BCR-ABL expressing bone marrow (BM) accelerated the onset of myeloid leukemia. We also observed that Egrl expression is down-regulated by BCR-ABL. Furthermore, we observed increased selfrenewal ability of BCR-ABL-expressing Egr1 KO BM, which correlated with increased leukemic potential and higher number of leukemia initiating cells. Our studies now demonstrate for the first time that Egrl behaves as a tumor suppressor in a mouse model of BCR-ABL driven leukemia, and provides the impetus to study the effect of altered Egr1 in Acute Myelogenous Leukemia (AML) where the overall five year survival rate remains low.

\section{RESULTS}

\section{Loss of Egr1 accelerates the onset of BCR-ABL driven leukemia}

In order to determine the effect of loss of Egrl on the initiation and progression of CML, we used a mouse model of CML (Figure 1). Specifically we transplanted lethally irradiated WT recipient mice with $\mathrm{BM}$ from WT or Egr ${ }^{-/}$mice infected with BCR-ABL-containing retrovirus (MSCV-IRES-GFP-BCR-ABL [MIGR1-BCR$A B L])$. We observed that all the mice transplanted with BCR-ABL-expressing BM null for Egrl succumbed to leukemia significantly faster than those mice transplanted with BCR-ABL expressing BM WT for Egrl $(P$ value $=$ 0.0001 ) (Figure $2 \mathrm{~A}$ and $3 \mathrm{G}$ ). We next inquired if there is a difference in the type of leukemia, and observed that regardless of the genotype of the donor BM most animals developed myeloid leukemia, with GFP+ BM cells from leukemic mice expressing Gr1 and not B220 (Figure 2B). Not only did mice display more rapid onset of leukemia (Figure 2A), at the time when mice were in a moribund state the disease was more severe in mice transplanted with Egr1///BCR-ABL BM than with WT/BCR-ABL $\mathrm{BM}$. This can be seen in tissue sections from spleens and lungs, where there was more pronounced infiltration of leukemia cells in $\mathrm{Egrl}^{-/ /} / \mathrm{BCR}-\mathrm{ABL}$ BM recipients than the WT/BCR-ABL BM recipients (Figure 3F). Furthermore, more leukemic cells (GFP+) were observed in the blood, $\mathrm{BM}$ and spleens (Figure 3A-3C) in mice transplanted with Egr 1/-/BCR-ABL BM compared to WT/BCR-ABL BM. Consistent with these findings, there is a greater increase in spleen and liver size in mice transplanted with $\mathrm{Egrl}^{-/-}$ BCR-ABL BM compared to WT/BCR-ABL BM (Figure 3D-3E). Taken together these data demonstrate that Egr1 behaves as a tumor suppressor in CML.

\section{Egr1 expression is down-regulated by BCR-ABL}

Given the evidence that Egrl has tumor suppressor functions, we wanted to assess how its expression is regulated by the $\mathrm{BCR}-\mathrm{ABL}$ oncogene. Using RNA from WT BM expressing BCR-ABL and empty vector control, a decrease in the level of Egrl mRNA in BCR-ABL expressing BM was observed (Figure 4A). The downregulation of Egrl by BCR-ABL was further confirmed in vivo in mice 20 days post-BMT. Spleens obtained from mice transplanted with BCR-ABL-expressing BM showed reduced expression of Egrl when compared to empty vector controls (Figure 4B). These results demonstrate that BCR-ABL down-regulated Egrl expression, either directly or indirectly, in both BM cells in vitro, and in the spleens of transplanted mice. It should be pointed out that although Egrl expression is reduced in BCR-ABL 
expressing hematopoietic cells, loss of Egrl, similar to other critical tumor suppressors like Pten and and p53 [18, 25], still has a significant impact on the progression of BCR-ABL induced leukemia.

\section{Egr1 deficiency is associated with decreased apoptosis, and increased cell viability and proliferation in response to $\mathrm{BCR}-\mathrm{ABL}$}

In an attempt to decipher how loss of Egrl accelerated the initiation and progression of CML, we investigated how its loss impacted on the survival and proliferation of BCR-ABL expressing BM cells. The change in viable cell number over time was ascertained using the MTS assay. It can be seen that $\mathrm{Egrl}^{-/ / \mathrm{BCR}-}$ ABL BM had increased number of viable cells compared to $\mathrm{WT} / \mathrm{BCR}-\mathrm{ABL} \mathrm{BM}$ cells, and this increase in cell number was more rapid (Figure 5A). To determine if this was due to altered apoptosis, cell proliferation, or a combination of both, apoptosis and proliferation were assessed. Egrl///BCR-ABL BM consistently showed a lower percentage of Annexin V positive cells, thus fewer apoptotic cells compared to WT/BCR-ABL BM (Figure $5 \mathrm{~B})$. In order to measure the rate of cell proliferation in vivo, mice transplanted with $E_{g r 1^{-/}}$or WT/BCR-ABL
BM were injected intraperitoneally with BrdU 20 days following BMT and assayed for BrdU incorporation. It was observed that $\mathrm{BM}$ from animals transplanted with Egr I $^{-/ /} / \mathrm{BCR}-\mathrm{ABL} \mathrm{BM}$ had an increased rate of DNA synthesis compared to BM from mice transplanted with WT/BCR-ABL BM, as shown by increased percentage of cells in S and G2-M phases (Figure 5C). Taken together, the decreased apoptosis and increased proliferation seen in $\mathrm{Egrl}^{-/ /} / \mathrm{BCR}-\mathrm{ABL} \mathrm{BM}$ is consistent with its increased leukemic potential.

Egr 1 $^{-1 /} /$ BCR-ABL BM transplanted mice are enriched in leukemia stem cells (LSCs) compared to WT counterparts

CML is a stem cell-derived disease and the accelerated development of CML due to Egrl deficiency (Figure $2 \& 3$ ) prompted us to examine how the loss of Egrl impacted leukemic stem/initiating cells (LSCs). First it was asked whether there was any quantitative difference in the stem cell population of mice transplanted with Egr1 $1^{-/} / \mathrm{BCR}-\mathrm{ABL}$ BM compared to the WT/BCR-ABL $\mathrm{BM}$ transplanted mice. BM was harvested from mice 20 days post-transplantation and the percentage of GFP+, Lin- cells was determined by FACS analysis. Our results

\section{Experimental Strategy}

Virus supernatant preparation

pMIG R1

pMIG210
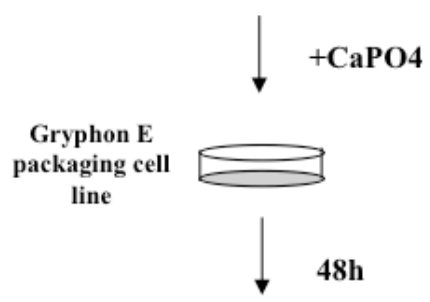

Retroviral supernatant

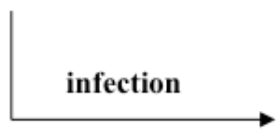

Enrich donor bone marrow progenitors

5-FU treat donor

mice

( Egr-1-/-, wild type )

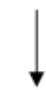

$\circ 00$

$\circ \circ$

Progenitors

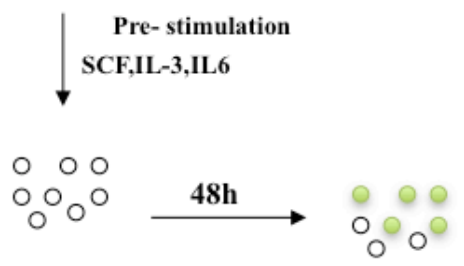

Progenitors

( expansion )
Infected progenitors

Bone marrow transplantation

Reconstituted recipients

( wild type )
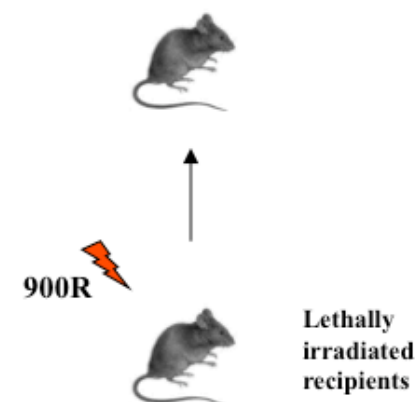

Figure 1: Schematic representation of the experimental strategy used in all BMT experiments described. 
showed that there was a significant $(P=0.0156)$ increase in the percent of $\mathrm{GFP}^{+} \mathrm{Lin}^{-}$cells from animals receiving $\mathrm{Egrl}^{-/ /} / \mathrm{BCR}-\mathrm{ABL} \mathrm{BM}$ (Figure 6A-6B). These results suggest a more rapid expansion of leukemic cells $\left(\mathrm{GFP}^{+}\right.$ $\mathrm{Lin}^{-}$) in $\mathrm{Egrl}^{-/ /} \mathrm{BCR}-\mathrm{ABL} \mathrm{BM}$ recipients.

Next, we set out to investigate if there is a difference in leukemia initiating cells by testing the ability of $\mathrm{Egrl}^{-/-}$ BCR-ABL BM to serially transfer leukemia in mice. WT or $E g r 1^{-/}$BM cells were transduced with BCR-ABL and transplanted into lethally irradiated mice; 14 days post- transplantation BM harvested from primary transplanted mice was transplanted into lethally irradiated secondary recipient mice. All Egr $1^{-/ /} / \mathrm{BCR}-\mathrm{ABL}$ recipient mice died by day 13 post-transplantation with a median survival of 11 days compared to $\mathrm{WT} / \mathrm{BCR}-\mathrm{ABL}$ recipient mice (median survival of 32 days) (Figure 6C), indicating that loss of Egrl resulted in enrichment of LSCs in the primary transplanted mouse. This is consistent with shorter survival time and more aggressive disease of these mice compared to WT counterparts.

A
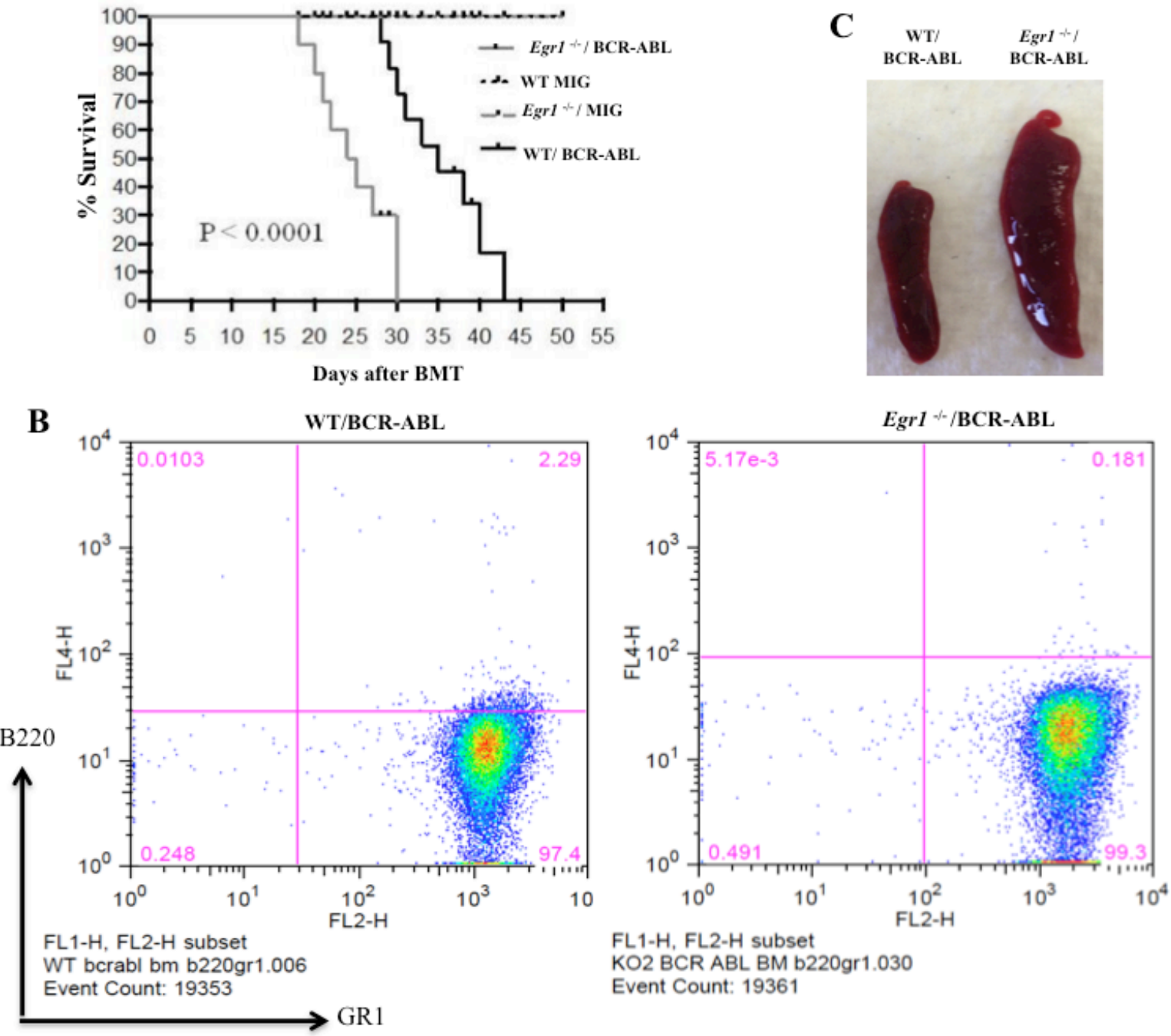

Figure 2: Loss of Egr1 accelerated CML development in mice. A. Kaplan-Meier survival curves for recipients of MIGR1 or MIG BCR-ABL-transduced BM cells from WT or $\mathrm{Egrl}^{-/}$donor mice. WT recipient mice were transplanted with BCR-ABL-expressing BM or MIGR1-expressing BM. Following transplantation, animals were observed for signs of disease and euthanized at first signs of morbidity. Statistical analysis used was Log-rank (mantel-Cox) test, P value $<0.0001$. Egr $1^{-/} / \mathrm{BCR}-\mathrm{ABL}(n=8)$ median survival 24.5 days, WT/BCR$\operatorname{ABL}(n=9)$ median survival 35 days. WT MIG $(n=4)$ and $\operatorname{Egr} 1^{-/-}$MIG $(n=4)$. Animals transplanted with MIGR1-infected BM did not show any signs of leukemia and were euthanized at the end of the experiments. B. Most leukemic mice exhibited myeloid disease. GFP+ BM cells harvested from leukemic mice when they exhibited signs of leukemia were prepared for antibody treatment, and incubated with anti-mouse Gr-1 and B220 antibodies. Following Facs, data analysis was performed using FloJo software. (Although all gates were not drawn at the $10^{2}$ positions on the y-axis, the cell populations are clearly observed and this does not impede the interpretation of the data). Eight to ten mice were analyzed from each genotype, and most of them (75-80\%) developed myeloid leukemia. C. Representatives spleens of mice transplanted with either WT/BCR-ABL or $E g r 1^{-/ / B C R}-\mathrm{ABL}$ BM cells at 18 days post-BMT. Spleens were removed from mice transplanted with either WT/BCR-ABL or $E g r 1^{-/ / B C R}-\mathrm{ABL}$ BM cells following euthanasia at 18 days post-BMT. 

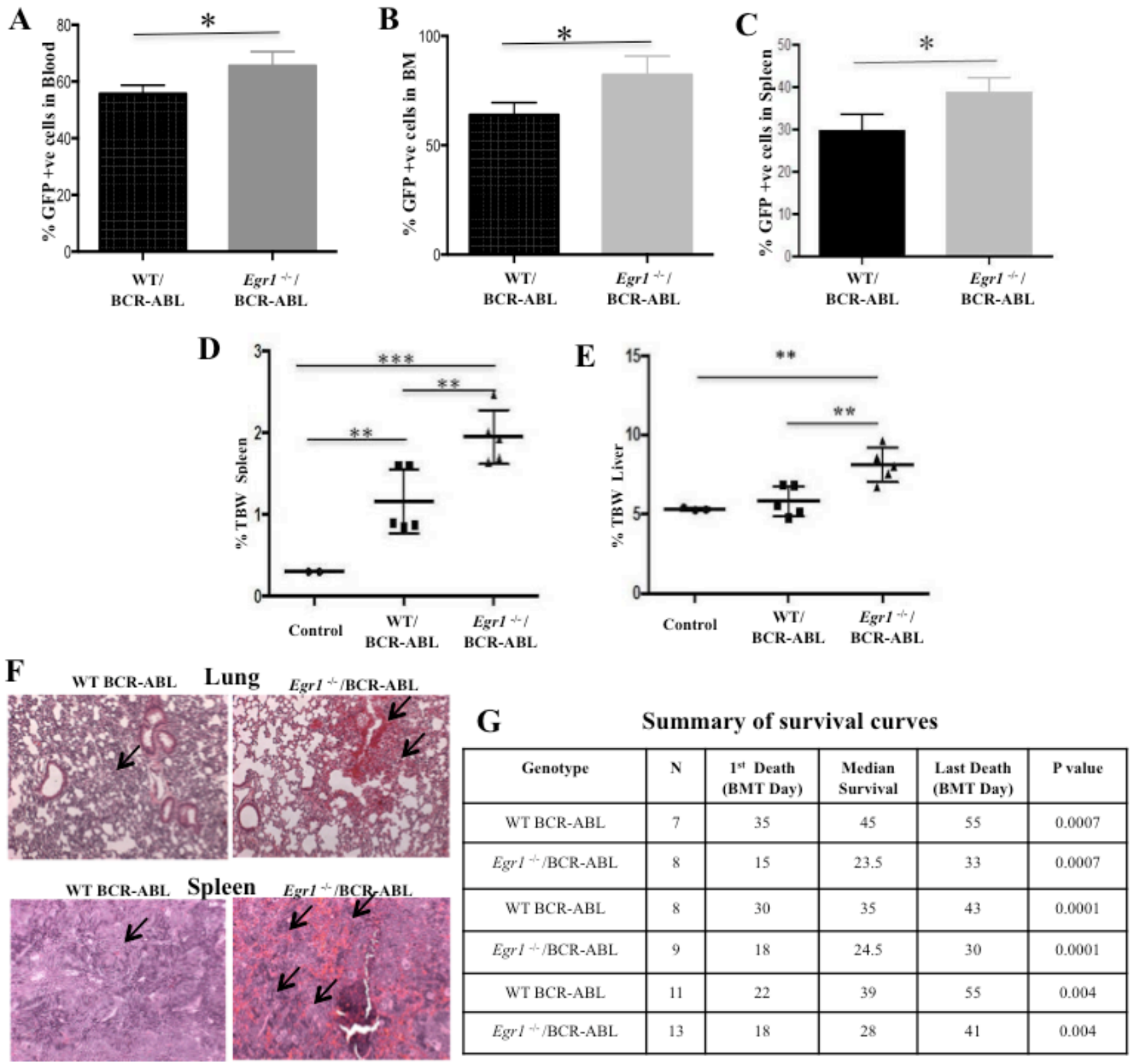

Figure 3: Loss of Egr1 accelerated CML development in mice. Lethally irradiated WT recipient mice were transplanted with BM from WT or Egr $1^{-/}$mice infected with BCR-ABL-containing retrovirus as detailed above. For panels A., B. and C., mice were euthanized when moribund. Facs analysis was done on peripheral blood (A), BM (B) and spleen cells (C) to assess $\% \mathrm{GFP}^{+}$cells. $(\mathrm{A}), P$ value $=0.0442$; $(\mathrm{B}), P$ value $=0.0370 ;(\mathrm{C}), P$ value $=0.0442 . \mathrm{WT} / \mathrm{BCR}-\mathrm{ABL} n=6, E g r 1^{-/} / \mathrm{BCR}-\mathrm{ABL} n=5$. D. \& E. Mice were euthanized 20 days after BMT, and spleen, liver and total body weight were determined. Mice transplanted with MIGR1-infected BM were used as controls. Values plotted represent the ratio of spleen or liver weight to total body weight (TBW). (D) Analysis of spleen weight. Spleens of $E g r 1^{-/ / B C R-A B L}$ -transplanted mice were significantly larger than in controls and in WT/BCR-ABL-transplanted mice. \% TBW spleen: Egr $1^{-/ / B C R-A B L}$

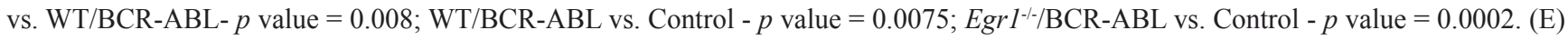
Analysis of liver weight. Livers of $E g r l^{-/} / \mathrm{BCR}-\mathrm{ABL}$-transplanted mice were significantly larger than those of animals transplanted with WT/BCR-ABL BM cells. \%TBW liver: $E g r 1^{-/ / B C R-A B L}$ vs. WT/BCR-ABL - significant, $p$ value $=0.0080$; WT/BCR-ABL vs. Control - not significant, $p$ value $=0.4163 ; E g r 1^{-/} / \mathrm{BCR}-\mathrm{ABL}$ vs. Control - Significant, $p$ value $=0.0053$. Control $(n=3)$, WT/BCR-ABL $(n=5)$, Egrl ${ }^{-/} / \mathrm{BCR}-\mathrm{ABL}(n=5) ; \mathbf{F}$. H\&E stained slides obtained from organs of leukemic mice showed more extensive infiltration of leukemic cells in Egr 1/-/BCR-ABL BM-transplanted mice compared to WT counterparts, in spleen and lungs. No clear infiltration of leukemic cells in the livers in either of the genotypes was observed. Five slides from organs from 3 mice for each genotype were examined; photograph is representative of what was observed for each genotype. Mice were displaying signs of leukemia when euthanized. Arrows indicate infiltration of leukemic cells. (10 X magnification). G. Summary of survival curves. Kaplan-Meier survival curves for recipients of MIGR1 or MIG BCR-ABL-transduced BM cells from WT or Egr $1^{-/-}$donor mice. 


\section{Loss of Egr1 increased self-renewal ability of BCR-ABL expressing BM}

To ascertain if loss of Egrl impacts on the selfrenewal properties of $\mathrm{BCR}-\mathrm{ABL}$ expressing $\mathrm{BM}$, serial re-plating colony assays were performed. $\mathrm{GFP}^{+}$cells

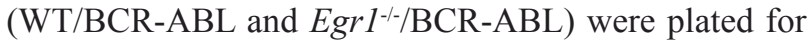
colonies, 8-12 days later colonies were counted and plated for the next round of colonies. Although there was no significant difference in the number of colonies for BCR$\mathrm{ABL}$ expressing WT and $\mathrm{Egrl}^{-/ /} \mathrm{BM}$ in the first round of plating, the Egr ${ }^{-/}$colonies were larger than WT. In the second round there was a significant reduction in the WT colony numbers in contrast to $\mathrm{Egrl}^{-/-}$cells. Furthermore,

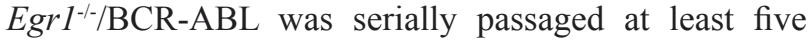
times without losing its ability to form colonies, whereas for WT/BCR-ABL cells colony numbers continued to be reduced with very few colonies by the third passage (Figure 7A). In addition, the colonies formed by $\mathrm{Egrl}^{-1 /}$
BCR-ABL BM cells continued to be much larger than the colonies formed by WT/BCR-ABL cells (Figure 7B). These data demonstrate that loss of Egrl increased selfrenewal ability in BCR-ABL-expressing BM.

Finally, to understand why loss of Egrl allowed for continuous colony formation for at least several passages, the immunophenotype of the cells comprising the colonies was determined. Specifically, the frequency and distribution of immature cell types, as well as the presence of differentiated cells was compared using cells from WT and $\mathrm{Egrl}^{-/}$colonies taken after three passages. It should be kept in mind that there were substantially fewer colonies in WT than Egr1 ${ }^{-/}$cells, and colony formation selects for proliferating cells. In spite of this, we observed that there were a higher percentage of $\mathrm{GFP}^{+} \mathrm{Lin}$ - and Lin- $\mathrm{Sca}-1^{+} \mathrm{c}-\mathrm{Kit}^{+}$(LSK) cells in the colonies formed by Egr $^{1 / /} /$ BCR-ABL BM than in the WT/BCR-ABL BM colonies (Figure 8A-8B). Interestingly, it was observed

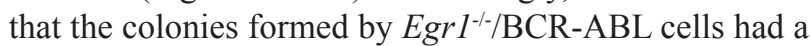

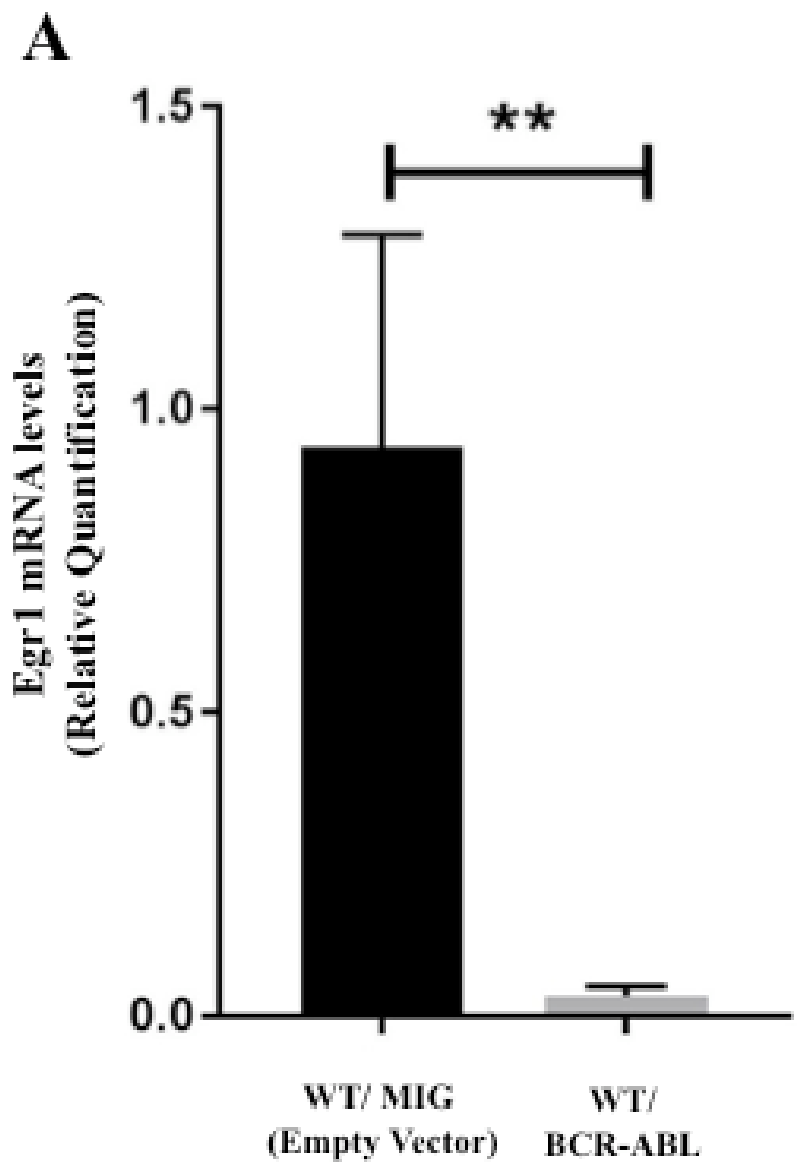

B

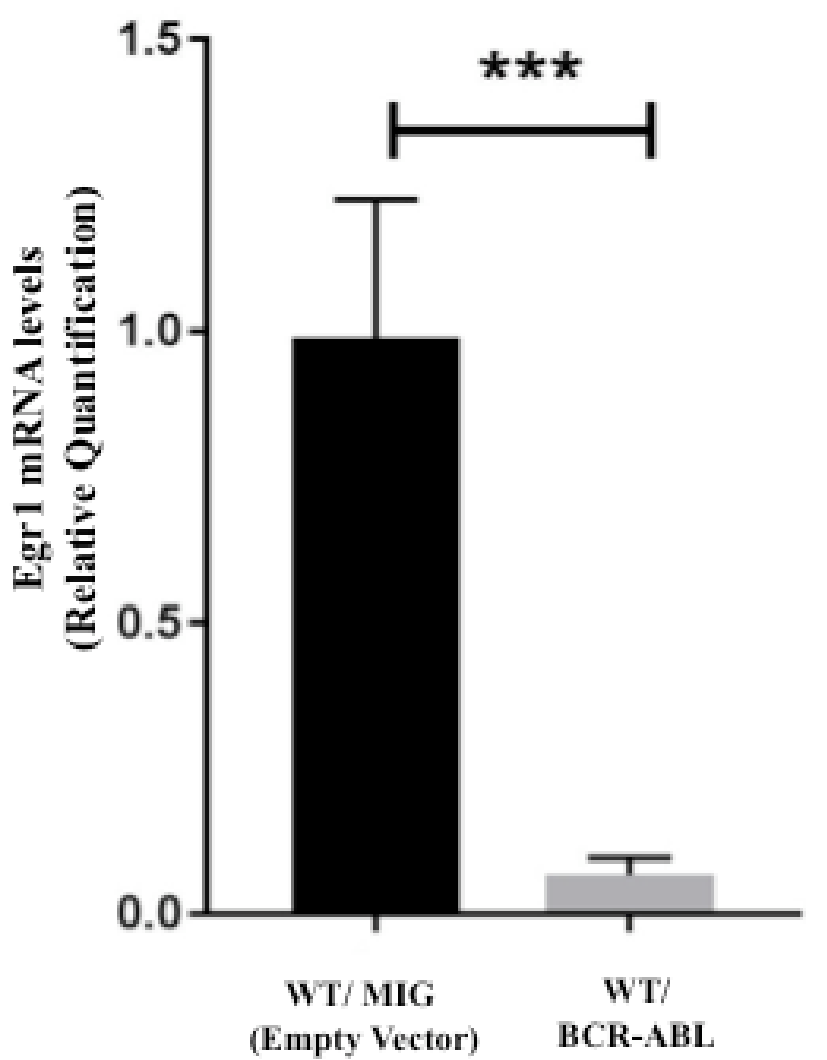

Figure 4: Egr1 expression is down-regulated by BCR-ABL. A. WT BM from 5-FU treated mice was transduced with either MSCV-BCR-ABL-IRES-GFP (MIG BCR-ABL) or the MSCV-IRES-GFP (MIGR1) retroviral vector. GFP ${ }^{+}$cells were selected by cell sorting, expanded, and RNA extracted. Total RNA was analyzed by real time PCR for Egrl expression using taqman probe. 18S rRNA probe was used as an internal control. Each sample comes from a different mouse. WT/MIG $n=4$, WT/BCR-ABL $n=5$. B. Spleens were harvested from mice transplanted with WT BM infected with either MIGR1 vector (control) or MIG BCR-ABL vector, 20 days post-BMT. Cells from whole spleens were dissociated and red blood cells removed prior to RNA extraction. WT/MIG $n=3, \mathrm{WT} / \mathrm{BCR}-\mathrm{ABL} n=8$. 
more homogeneous population than the WT counterpart, with most of its cells being LSK (73.9\%) and Lin ${ }^{-}$Sca-1

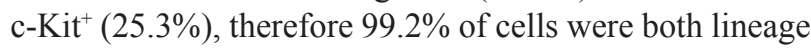
negative and positive for c-Kit (Figure 8C). In contrast, very few WT cells were Lin-Sca1-cKit+. In addition, all differentiation markers were higher in WT than Egr $1^{-/-}$ BCR-ABL -expressing cells (Figure 8D). Taken together, these data show that $E g r 1^{-/} / \mathrm{BCR}-\mathrm{ABL} \mathrm{BM}$ has higher self-renewal ability than WT/BCR-ABL BM, and is accompanied by an increase in Lin-Kit+ cells.

\section{DISCUSSION}

To study the role of Egrl as a tumor suppressor of myeloid leukemia, a mouse model of BCR-ABL driven leukemia was employed. We have shown that loss of Egrl accelerated the development of leukemia in the bone marrow transplantation and transduction model of CML. Furthermore, loss of Egrl is associated with increased numbers of LSCs, which have enhanced ability to self-renew. Most of the transplanted mice developed a CML-like disease, while a smaller group developed a B cell lymphoblastic leukemia [B-ALL]-like disease (data not shown). The two diseases observed in our BM transplantation have been reported in other laboratories [26-28]; the incidence of B-ALL-like leukemia in both

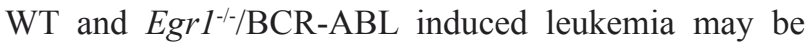
mouse strain specific.

The BM from $E g r 1^{-/ / B C R}-\mathrm{ABL}$ leukemic mice were enriched with lineage negative BCR-ABLexpressing cells, compared to WT counterparts (Figure
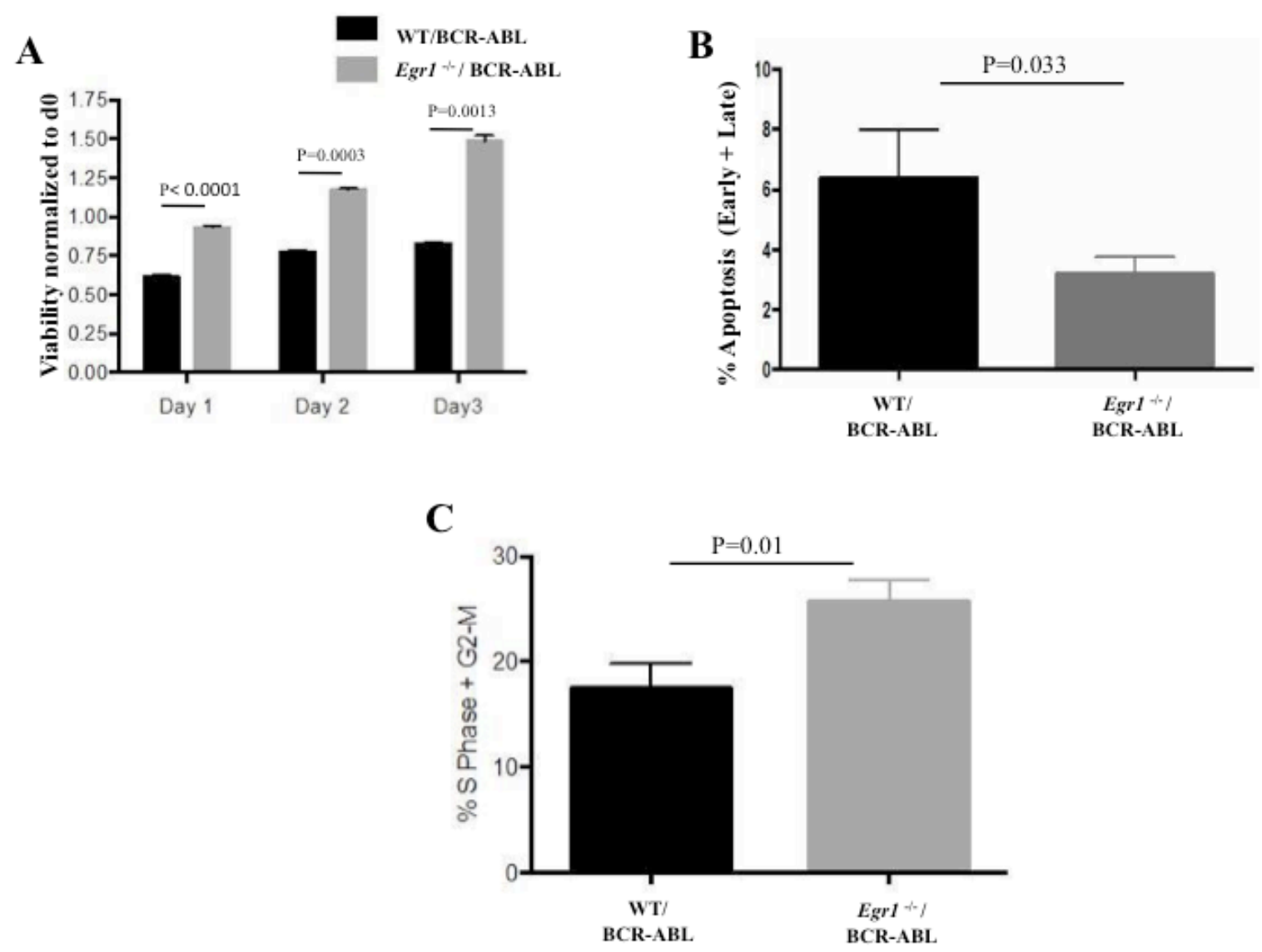

Figure 5: Egrl deficiency is associated with decreased apoptosis, and increased cell viability and proliferation in response to BCR-ABL. For A. and B., Egrl ${ }^{-/}$and WT BM cells were infected with BCR-ABL expressing vectors, and GFP+ cells were sorted and used for analysis. Viability was assessed using MTS assay by normalizing to day 0. BCR-ABL infected Egr $1^{-/}$BM cells showed enhanced viability at the three time-points compared to BCR-ABL infected WT BM cells. Day $1-P$ value $<0.0001$; Day $2-P$ value $=0.0003$; Day $3-P$ value $=0.0013$. Data is representative of five independent experiments. $(\mathrm{B}) \mathrm{GFP}+$ sorted BM cells were incubated with Annexin V antibody and PI, and Facs analysis was done. BCR-ABL infected Egr $1^{-/}$BM have fewer Annexin V positive cells, thus fewer apoptotic cells, than BCR-ABL infected WT BM, $P$ value $=0.033$. Represented here are the percentage of early $\left(A n n e x i n \mathrm{~V}^{+}\right.$only) and late (Annexin $\mathrm{V}^{+}$and $\mathrm{PI}^{+}$) apoptosis. Data is representative of 3 independent experiments. C. 20 days following BMT, mice were injected intraperitoneally with BrdU and euthanized after two hours. BM was harvested and prepared for cell proliferation assessment using BrdUassay. $P$ value = 0.01. WT/BCR-ABL: G1-55.3\%, S-8.3\%, G2-M-11.1\%; Egr 1///BCR-ABL: G1-60.3\%, S-15.2\%, G2-M-12.9\%. Data

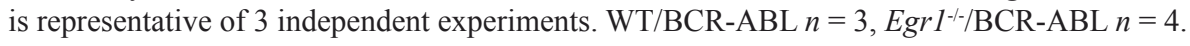


6A-6B), supporting a role for loss of Egrl increasing the LSC population. Min et at.[29] observed that Egr ${ }^{-/-}$ HSCs cycle more frequently than WT; however, the excess HSCs produced do not remain in the BM but rather leave the BM niche and enter the blood stream increasing the number of circulating HSCs [29]. It is possible that loss of Egrl alters the homeostasis of LSCs, similar to its effect on HSCs, by increasing the population of cycling cells, thereby accounting for the observed early and consistent elevation of LSCs in leukemic mice. Consistent with these observations, loss of Egrl significantly enhanced the selfrenewal capacity of BCR-ABL-expressing BM. Whereas the colony replating of $\mathrm{WT} / \mathrm{BCR}-\mathrm{ABL}$-expressing $\mathrm{BM}$ declines rapidly with few or no colonies by the third cycle, loss of Egrl was associated with continued colony formation at least until the fifth cycle, with no sign of abating (Figure 7). In addition, the cells comprising the
Egr $^{-/-}$colonies were more homogenous than WT, enriched for LSK cells, with the remainder being c-Kit positive; $99.2 \%$ of cells were both lineage negative and positive for c-Kit (Figure 8C).

The role of Egrl as a positive regulator of myeloid differentiation, as well as its role in HSC homeostasis, could, in combination, participate in the observed increase in primitive cells and lack of differentiated cells in $\mathrm{Egrl}^{-}$ -/BCR-ABL expressing cells. These observations are consistent with the loss of Egrl resulting in more rapid onset and more aggressive leukemia, and the increased burden of lineage negative cells in the BM of BCR-ABLinduced leukemia. The effect of serial passaging of Egr ${ }^{-}$ -/BCR-ABL expressing cells, as done in colony assays, on their ability to promote leukemia compared to nonpassaged cells would be informative. Furthermore, within that context how the gene expression signature is altered

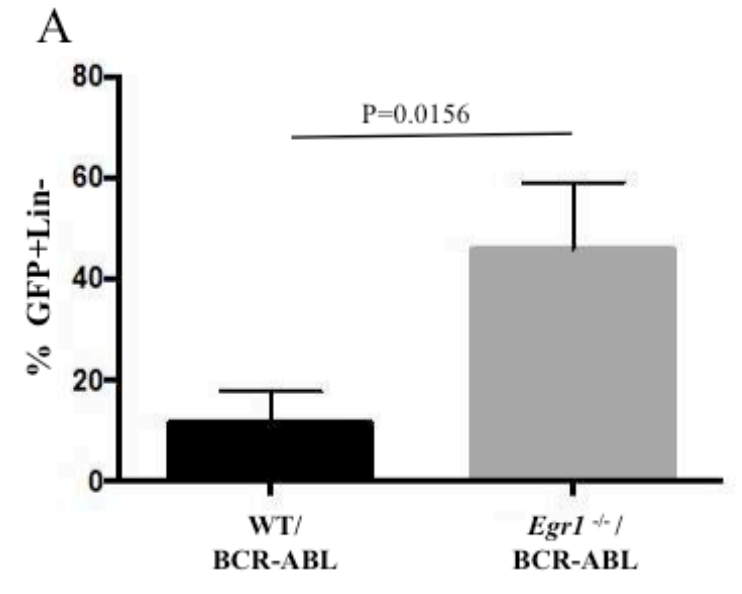

$\mathrm{B}$
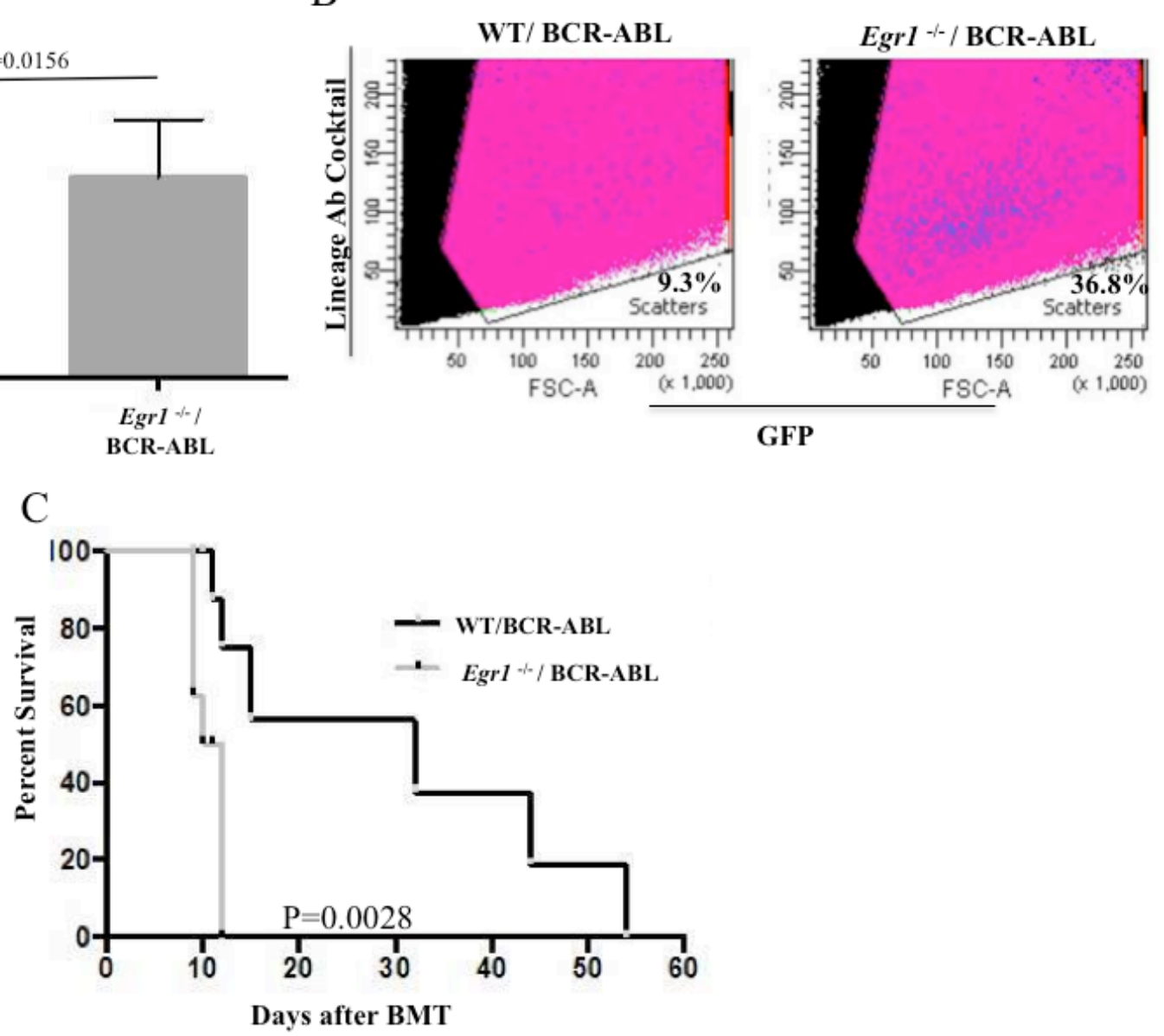

Figure 6: Loss of Egr1 increased leukemia initiating cells. A.-B. The leukemia stem cells are enriched in BM from mice transplanted with $\mathrm{Egrl}^{-/} / \mathrm{BCR}-\mathrm{ABL}$ BM compared to WT/BCR-ABL BM. BM was harvested 20 days post BMT. Representative Facs data of $\mathrm{GFP}^{+} \mathrm{Lin}^{-}$cells from one of the mice analyzed for each genotype. $P$ value $=0.0156$. $(n=3$ for each genotype $) \mathrm{C}$. BM from primary transplanted mice was harvested on day 14 post BMT and red blood cells were lysed. $1 \times 10^{6} \mathrm{BM}$ cells from primary transplanted mice were injected into lethally irradiated secondary recipient mice, and Kaplan-Meier survival curves for recipients are shown. Statistical analysis was performed using Log-Rank (Mantel-Cox) test. $P$ value $=0.0028$. Median Survival: WT/BCR-ABL 32 days; $E g r 1^{-1 /} / \mathrm{BCR}-\mathrm{ABL} 11$ days. WT/BCR-ABL $(n=6)$ and Egr $^{-/ /} / \mathrm{BCR}-\mathrm{ABL}(n=7)$. 
in association with passaging would inform us on how loss of Egrl interacts with different signaling pathways to modify the leukemic phenotype and how it changes over time.

Similar to other critical tumor suppressors like Pten and Msrl [18, 36], it was observed that Egrl expression is down-regulated by BCR-ABL both in vitro as well as in vivo (Figure 4). This is consistent with its tumor suppressor role; failure to reduce Egrl may limit or inhibit leukemia initiation and progression. As reported in this manuscript, total loss of Egrl allows the leukemia to be initiated and to progress more rapidly.

EGR1 has been shown to regulate cell growth, proliferation, and apoptosis in different cell types by engaging key signaling pathways such as TGF $\beta 1$, PTEN, p53 and fibronectin [17, 31, 34]. It will therefore be interesting to study their functional hierarchy and relative contribution in CML by performing pharmacological inhibitor studies.

Previous reports have revealed an important role for Egr1 in different hematological conditions: Egr1 regulates hematopoietic stem cell proliferation and localization [13]; haploinsufficiency of Egr1 promotes N-ethyl-nitrosourea (ENU) induced myeloproliferative disorder (MPD) [30]; concordant loss of Tp53 in Egr1 and Apc haploinsufficient HSPCs leads to AML in mice
[31]; miRNA-181a modulates acute lymphoblastic leukemia by targeting Egr1[32]; miRNA-146a modulates B-cell oncogenesis through Egr1 [33]; and the NF- $\mathrm{BB} /$ EGR1/BIM pathway regulates cytotoxicity of mTOR dual inhibitors in malignant lymphoid cells[34]. Our data provide an important extension of this notion, showing for the first time that loss of Egrl accelerates BCR-ABL driven chronic myelogenous leukemia.

The studies on Egr1 in CML provide the impetus to study the effect of altering Egr1 expression in AML where the overall five year survival rate remains low. The effect of loss of Egr1 in CML could reflect its established functions in normal hematopoiesis, maintaining quiescence of HSCs and driving terminal differentiation to the monocyte/macrophage lineage. Gain of function studies should validate these conclusions and provide further rationale for studying the effect of increased Egr1 as a therapeutic target in AML.

In conclusion, the results obtained indicate that Egrl is a critical tumor suppressor of BCR-ABL driven chronic myelogenous leukemia providing the impetus to further investigate the role of Egrl and explore its potential as a therapeutic target in other cancers.

A

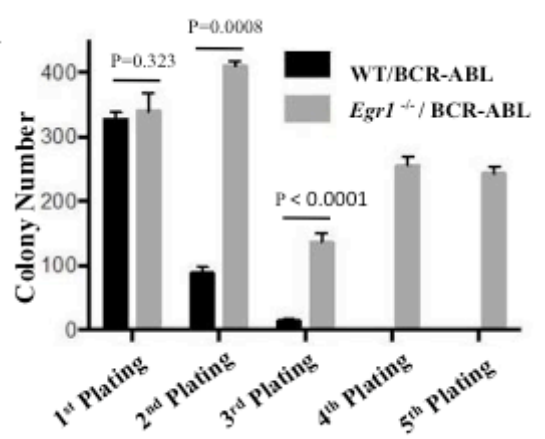

B

\begin{tabular}{|c|c|c|c|c|c|}
\hline \multicolumn{6}{|c|}{ Summary of Colony Forming Experiments } \\
\hline Exp. \# & Genotype & $\begin{array}{l}\text { Avg. Colony \# } \\
1^{\text {tt Plating }}\end{array}$ & $\begin{array}{c}\text { Avg. Colony \# } \\
2^{\text {ad }} \text { Plating }\end{array}$ & $\begin{array}{c}\text { Avg. Colony \# } \\
3^{\text {red }} \text { Plating }\end{array}$ & $\begin{array}{l}\text { Avg. Colony \# } \\
4^{\text {th }} \text { Plating }\end{array}$ \\
\hline 1 & WT/BCR-ABL & 196 & 88 & 35 & 1 \\
\hline 1 & $E_{g r l} / / \mathrm{BCR}-\mathrm{ABL}$ & 212 & 266 & 148 & 150 \\
\hline 2 & WT/BCR-ABL & 327 & 88 & 14 & 2 \\
\hline 2 & $E_{g r} 1 / / \mathrm{BCR}-\mathrm{ABL}$ & 340 & 410 & 137 & 243 \\
\hline 3 & WT/BCR-ABL & 306 & 21 & 0 & $-*$ \\
\hline 3 & $\mathrm{Egr}_{1} 1 * / \mathrm{BCR}-\mathrm{ABL}$ & 535 & 122 & 44 & 72 \\
\hline
\end{tabular}

* There were not sufficient cells from third round of plating to set up the 4th plating for WT BCR-ABL

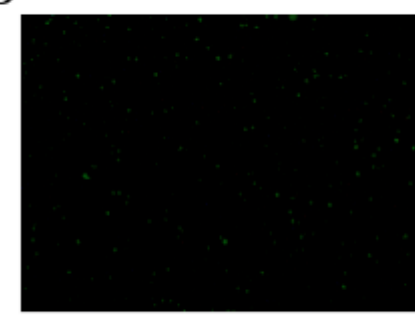

WT/BCR-ABL Fourth Plating
\# (number) Avg. (Average)

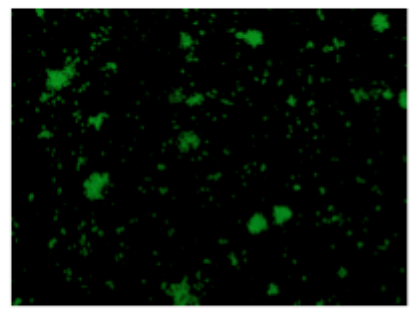

Egr1 ${ }^{\sim-} /$ BCR-ABL Fourth Plating

Figure 7: Loss of Egr1 enhanced self-renewal capacity of BCR-ABL expressing BM. GFP ${ }^{+}$cells (WT/BCR-ABL and $E g r 1^{-1-}$ $\mathrm{BCR}-\mathrm{ABL}$ ) were plated for colonies, 8-12 days later colonies were counted and plated for the next round of colonies. A. Data from one representative experiment (experiment 2 shown in Table). Statistical analysis: first round, $P$ value $=0.3232$ not significant; second round: $P$ value $=0.0008$, third round: $P$ value $<0.0001$; fourth round: $P$ value $<0.0001$. Colony number is average number of colonies obtained from three $35 \mathrm{~mm}$ dishes. B. Photomicrograph of representative plate from $4^{\text {th }}$ round of plating, $4 \mathrm{X}$ magnification. 


\section{MATERIALS AND METHODS}

\section{Cell lines and primary bone marrow cells}

Phenix Ecotropic (Eco) and Gryphon Ecotropic (Eco) (purchased from Allele Biotech) retrovirus packaging cell lines were used to generate retrovirus. Both cell lines were created by placing constructs capable of producing gag-pol and envelop proteins for ecotropic viruses into 293T cells. Cells were cultured in Dulbecco's modified Eagle's medium (DMEM) (Corning Cellgro) supplemented with $10 \%$ fetal bovine serum (FBS) (Gibco) and $100 \mathrm{U} / \mathrm{ml}$ penicillin, $100 \mu \mathrm{g} / \mathrm{ml}$ streptomycin (Corning CellGro). Cell culture was carried on a humidified tissue culture incubator with $5 \% \mathrm{CO}_{2}$ at $37^{\circ} \mathrm{C}$. Primary bone marrow (BM) cells were harvested from C57BL6 mice and $\mathrm{Egrl}^{-/-}$C57BL6 mice injected with $200 \mathrm{mg} / \mathrm{g}$ of 5-Fluourouracil (5-FU) 4-5 days prior to BM harvest. After BM harvest, the red blood cells were lysed with Ammonium Chloride Potassium (ACK) lysing buffer (Gibco), cell pellet was washed with phosphate buffered saline (PBS) (Gibco Cellgro) and the white blood cells were then cultured in Iscove's modified Dulbecco's medium (IMDM) (Corning Cellgro) supplemented with
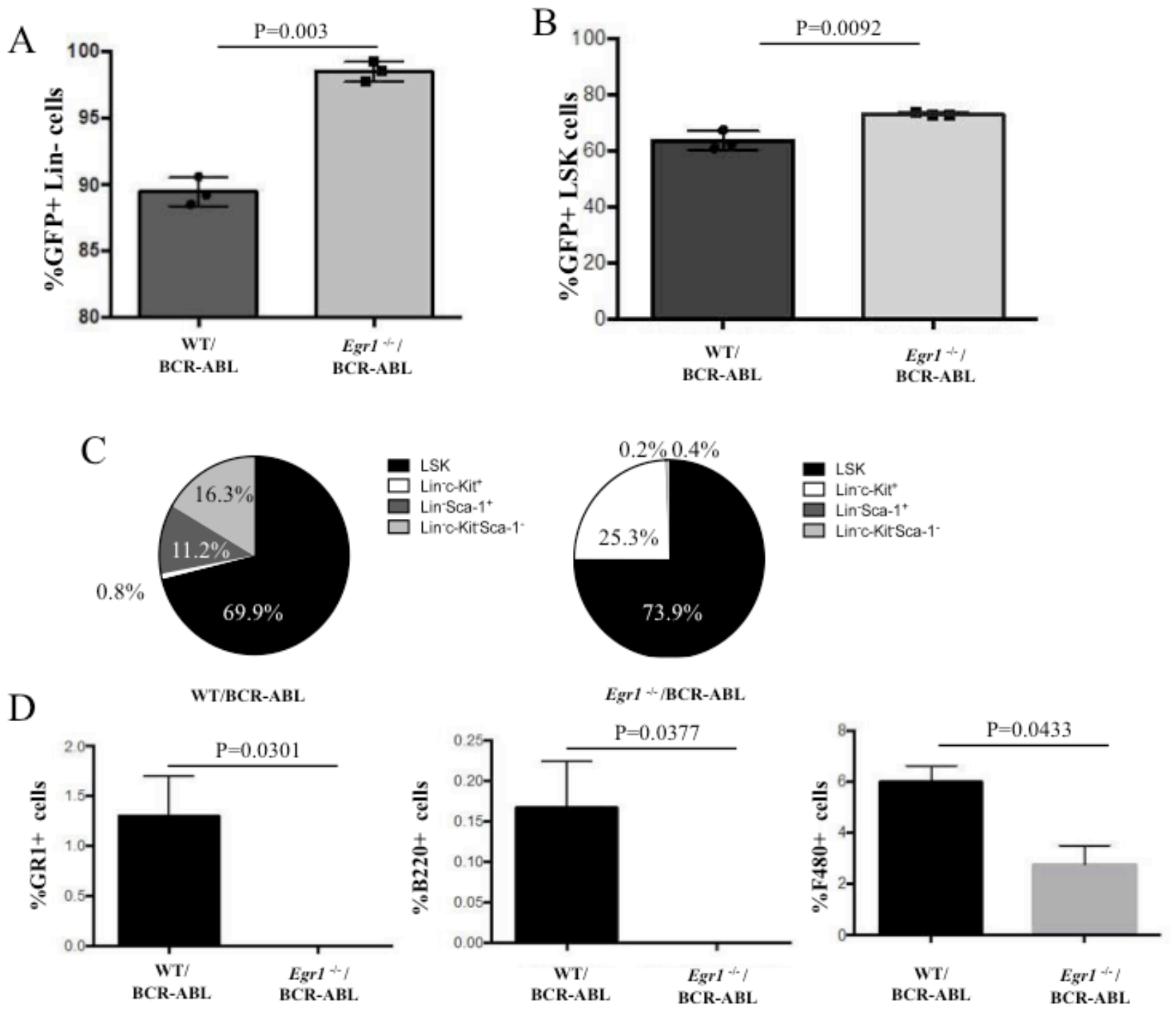

Figure 8: Immuno-phenotype of cells from colonies from BCR-ABL expressing WT- and Egr $\mathbf{1}^{-/}$BM. After counting colony numbers on passage 3, cells were re-suspended in PBS and washed to remove methylcellulose; then stained with the indicated antibodies for Facs analysis. A. Percent of total cells that are GFP+, Lin-. $P$ value $=0.0003$. B. Percent of total cells that are GFP ${ }^{+}$and LSK. $P$ value $=0.0092$. C. Distribution of Lin- cell population for Sca-1 and c-Kit expression. D. Cells from WT/BCR-ABL colonies have higher number of cells expressing lineage markers (Gr-1, B220 and F4/80). Statistical analysis: Gr-1 $P$ value $=0.0301 ; \mathrm{B} 220: P$ value $=0.0377$; F-480 $P=$ value 0.0433 . 
10\% FBS, $100 \mathrm{U} / \mathrm{ml}$ penicillin, $100 \mu \mathrm{g} / \mathrm{ml}$ streptomycin and the cytokines Stem Cell Factor (SCF) $(50 \mathrm{ng} / \mathrm{ml})$, Interleukin-6 (Il-6) 15 (ng/ml) and Interleukin-3 (Il-3) $(10 \mathrm{ng} / \mathrm{ml})$ (Peprotech). Cell culture was maintained in a humidified tissue culture incubator with $10 \% \mathrm{CO}_{2}$ at $37^{\circ} \mathrm{C}$.

Mice

C57BL6 mice and Egr1 ${ }^{-/}$C57BL6 mice were obtained from Michelle LeBeau (University of Chicago) with permission from J. Millbrandt (Washington University School of Medicine in Saint Louis), who established the strain [35]. Mice were maintained in a temperature and humidity-controlled environment at Temple University's Health Science campus animal facilities. The Temple University Institutional Animal Care and Use Committee (IACUC) approved all animal studies. Since $\mathrm{Egrl}^{-/-}$female mice are sterile breeding for generation of $\mathrm{Egrl}^{-/-}$mice was done using $\mathrm{Egrl}^{-/-}$male mice with Egrl ${ }^{+/}$females. Pups were ear-tagged and tails clipped at the time of weaning. Tail clippings used for genotyping, were put in lysis buffer solution $(50 \mu \mathrm{l})$ overnight in $55^{\circ} \mathrm{C}$ water bath. Afterwards $300 \mu$ of DNase free water was added to the tubes containing individual lysed tail clippings and boiled for 5 minutes. Once cooled this mix of tail, buffer and water was used as DNA template for PCR reactions to determine the presence or absence of the Egrl gene. Primers used were: Egrl WT R - 5'-ggg cac agg gga tgg gaa tg-3'; Egrl WT F - 5'-aac cgg ccc agc aag aca cc-3'; Egrl Neo F - 5'- ctc gtg ctt tac ggt atc gc-3'. All three primers have to be in each PCR reaction to observe Egrl status on the sample.

\section{Bone marrow transduction and transplantation}

Bone marrow cells were harvested from mice that were injected with $200 \mathrm{mg} / \mathrm{g}$ of 5-FU intra-peritoneally 4-5 days prior to $\mathrm{BM}$ harvest. 48 hours after harvest, cells were subjected to 2-4 rounds of spin infections with retroviral supernatant carrying MSCV-IRES-GFP (also called MIGR1) or MSCV-IRES-BCR-ABL-GFP (also called MIG BCR-ABL) (generated using Phoenix Eco or Gryphon Eco cells), in the presence of polybrene (Sigma) $(10 \mathrm{mg} / \mathrm{ml})$ and cytokines (SCF 20ng/ml, Il-3 and Il-6 $8 \mathrm{ng} / \mathrm{ml}) .24$ hours after the last round of infections, cells were analyzed on BD FACS Calibur to determine the efficiency of infection (percentage of $\mathrm{GFP}^{+}$cells). Retro-orbital injection of $3 \times 10^{3} \mathrm{GFP}^{+}$cells and $4.97 \times 10^{5}$ uninfected cells was done into each lethally irradiated WT recipient mice (1 irradiation dose of 900 Rads using a RS2000 Biological Irradiator) (Rad Source). Secondary BM transplantation was done using BM from primary BM transplanted mice. After removing red blood cells with ACK lysis, cells were washed with PBS and centrifuged at 1000 RPM for 5 minutes; then, the cell pellet was resuspended in PBS. 1 $10^{6}$ white blood cells were injected into each lethally irradiated secondary recipient mice by retro orbital injection[36].

\section{Flow cytometric analysis}

$\mathrm{BM}$ and spleen cells were dissociated and treated with ACK lysis buffer to lyse the red blood cells, washed with PBS and suspended in PBS $+1 \%$ BSA (FACS buffer). Antibody staining was performed on ice for 30 minutes unless specified by the maker. Flow cytometric analysis was carried in a BD FACS Calibur or a BD LSR II flow cytometer as described previously [37]. Data analysis was performed using FACS Diva (BD Biosciences) or FlowJo software.

\section{Antibodies}

PerCP-Cy 5.5 Mouse lineage cocktail, APC c-Kit, APC Gr-1, PE B220, APC anti-BrdU and Fc block (CD16/ CD32) were all from BD Pharmingen. Pacific blue antimouse Ly-6A/E (Sca-1) was purchased from Biolegend. PE F4/80, APC CD11b and APC Annexin V were from eBioscience.

\section{Analysis of cell viability}

Sorted $\mathrm{GFP}^{+} \mathrm{BM}$ cells expressing either MSCVIRES-GFP or MSCV-IRES-BCR-ABL-GFP were cultured in IMDM supplemented with $10 \% \mathrm{FBS}, 100 \mathrm{U} /$ $\mathrm{ml}$ penicillin, $100 \mu \mathrm{g} / \mathrm{ml}$ streptomycin and the cytokines SCF (50 ng/ml), Il-6 (15 ng/ml) and Il-3 (10 ng/ml). 3-7 days post-sorting cells were plated in 96 wells plate at a density of $1 \times 10^{4}$ cells/well. Afterwards at the $0,24,48$ and 72 hours time points $20 \mu \mathrm{l}$ of Cell Titer $96^{\circledR}$ Aqueous One Solution Cell Proliferation Assay (Promega) were added to each well. Plates were incubated for 1-4 hours in a humidified $5 \% \mathrm{CO}_{2}$ tissue culture incubator, according to manufacture's protocol. The absorbance was then recorded at 490nm using a 96-well Victor plate reader (Perkin Elmer).

\section{Analysis of apoptosis}

Cell apoptosis was measured using Annexin VAPC apoptosis detection kit along with Propidium Iodide (PI) staining solution according to the manufacturer instructions (eBioscience). WT/BCR-ABL and $\mathrm{Egrl}^{-/ /}$ $\mathrm{BCR}-\mathrm{ABL}$ infected $\mathrm{BM}$ cells were washed in PBS once then washed in binding buffer supplied in the kit. Cells were incubated with Annexin V antibody for 10-15 minutes at room temperature, washed with wash buffer supplied in the kit and resuspended in binding buffer, at this point $5 \mu$ of PI solution was added to the cells. Flow 
cytometric analysis of cells was performed within 2 hours of staining using FACSCalibur or LSR II, and data was analyzed on either FlowJo or FACSDiva software.

\section{Analysis of cell proliferation using bromodeoxyuridine (BrdU) assay}

Mice transplanted with WT/BCR-ABL and Egr ${ }^{-}$ /-/BCR-ABL were intraperitoneally injected (IP) with $2 \mathrm{mg}$ of BrdU solution $(10 \mathrm{mg} / \mathrm{ml}$ solution of BrdU in 1 $\mathrm{X}$ DPBS). 2 hours after injection, mice were euthanized and bone marrow was harvested. Staining was performed according to manufacturer's protocol (BD Pharmingen). Briefly, cells were fixed and permeabilized with BD Cytofix/Cytosperm buffer for 30 minutes on ice, then washed with $1 \mathrm{X}$ BD Perm/Wash buffer. Afterwards cells were incubated on ice for 10 minutes with BD Cytosperm Permeabilization Plus and washed again with wash buffer. Cells were then re-fixed for 5 minutes on ice with the fixing buffer, and again washed before being treated with DNase for 1 hour at $37^{\circ} \mathrm{C}$. After DNase treatment cells were once more washed in wash buffer and incubated with APC conjugated anti-BrdU antibody for 20 minutes at room temperature. Following incubation with the antibody, cells were washed in wash buffer one last time and suspended in PI solution. Stained cells were acquired on LSR II and analyzed using FACS Diva software.

\section{Serial re-plating colony assay}

WT and Egrl/- BM expressing BCR-ABL were obtained following infection of appropriate $\mathrm{BM}$ with the MSCV-IRES-BCR-ABL-GFP vector, as described in section "Bone Marrow Transduction and Transplantation" followed by sorting to select for GFP+ expression. The cells were suspended in IMDM with $2 \%$ FBS at a concentration of $2 \times 10^{5}$ cells $/ \mathrm{ml}$. Then, $0.4 \mathrm{ml}$ of this cell suspension was added to $4 \mathrm{ml}$ of MethoCult (StemCell Technologies). Cells were mixed thoroughly and $1.1 \mathrm{ml}$ of MethoCult + cells was dispensed into each $35 \mathrm{~mm}$ dish. Final cell concentration was $2 \times 10^{4}$ cells/dish. Dishes were incubated at $37^{\circ} \mathrm{C}, 5 \% \mathrm{CO}_{2}$, with $\geq 95 \%$ humidity for 8-12 days to allow colonies to form. Colonies were then counted; the cells were rinsed with PBS, counted and replated in new media at a concentration of $2 \times 10^{4}$ cells/ dish to test their ability to form colonies upon secondary plating. This process was repeated as indicated for each experiment.

\section{RNA extraction and quantitative polymerase chain reaction}

WT/BCR-ABL and Egr1/-/BCR-ABL GFP sorted $\mathrm{BM}$, as well as dissociated spleen cells from animals transplanted with WT/BCR-ABL or Egr ${ }^{-1 /}$ BCR-ABL $\mathrm{BM}$, were washed in PBS, spun in a centrifuge at 1000 RPM for 5 minutes, then supernatant was removed and cell pellet frozen at $-80^{\circ} \mathrm{C}$ freezer until RNA extraction. RNA was extracted from samples using RNaesy kit (Qiagen) according to manufacturer's protocol. A reverse transcriptase polymerase chain reaction (RT-PCR) was performed to convert RNA to c-DNA using TaqMan Reverse Transcription reagents (Applied Byosistems) according to manufacturer's protocol. c-DNA was then used to run the real time polymerase chain reaction analysis (qRT-PCR) in a StepOne Real Time PCR machine (Applied Byosistems) as described previously [38]. Probes used were the following, all purchased from Life Technologies: Mm00656724_m1 (mouse Egr1), and Mm04277571_S1, for 18, which was used as endogenous control.

\section{Tissue fixation and slide preparation}

Spleens, liver and lungs were dissected from moribund mice and fixed in a $4 \%$ formaldehyde solution immediately. Slides from these fixed organs (prepared by Histotechnology Core, The Wistar Institute) were stained with Hematoxylin \& Eosin (H\&E) and examined using an Olympus inverted microscope with digital imaging.

\section{Authorship contributions}

S.M. planned, designed and performed all experiments, analyzed data, prepared figures, and wrote the first draft of manuscript; A.M. prepared figures, wrote and critically revised the manuscript; X.S. assisted with experiments and technical support; K.M assisted with experiments and technical support; D.L. supervised the project and revised the manuscript; B.H. conceived the study, supervised the project, interpreted data, wrote and revised the manuscript.

\section{ACKNOWLEDGMENTS}

This work was supported by the National Institutes of Health 5 RO1 CA81168-08 (BH), MD Anderson Cancer Center Leukemia SPORE P50 CA100632 (BH) \& Temple University Bridge Funding (BH). We thank Dr. Xiaoxuan Fan (Temple Flow Cytometry) for his technical assistance.

\section{CONFLICTS OF INTEREST}

The authors declare no conflict of interest.

\section{REFERENCES}

1. Sukhatme VP, Cao XM, Chang LC, Tsai-Morris $\mathrm{CH}$, 
Stamenkovich D, Ferreira PC, Cohen DR, Edwards SA, Shows TB, Curran T, Beau MML, Adamson ED. A zinc finger-encoding gene coregulated with c-fos during growth and differentiation, and after cellular depolarization. Cell. 1988; 53:37-43.

2. Thiel G, Cibelli G. Regulation of life and death by the zinc finger transcription factor Egr1. J Cell Physiol. 2002; 193:287-292.

3. Krishnaraju K, Hoffman B, Liebermann DA. The zinc finger transcription factor Egr1 activates macrophage differentiation in M1 myeloblastic leukemia cells. Blood. 1998; 92:1957-1966.

4. Krishnaraju K, Hoffman B, Liebermann DA. Early growth response gene 1 stimulates development of hematopoietic progenitor cells along the macrophage lineage at the expense of the granulocyte and erythroid lineages. Blood. 2001; 97:1298-1305.

5. Magimaidas A, Badolia R, Madireddi P, Bhavanasi D. As"SIRT"ing the role of an epigenetic modifier in hematopoietic stem cell homeostasis. Stem Cell Investig. 2016; 3:56.

6. Gibbs JD, Liebermann DA, Hoffman B. Terminal myeloid differentiation is uncoupled from cell cycle arrest. Cell Cycle. 2007; 6:1205-1209.

7. Krishnaraju K, Nguyen HQ, Liebermann DA, Hoffman B. The zinc finger transcription factor Egr1 potentiates macrophage differentiation of hematopoietic cells. Mol Cell Biol. 1995; 15:5499-5507.

8. Nguyen HQ, Hoffman-Liebermann B, Liebermann DA. The zinc finger transcription factor Egr1 is essential for and restricts differentiation along the macrophage lineage. Cell. 1993; 72:197-209.

9. Stoddart A, McNerney ME, Bartom E, Bergerson R, Young DJ, Qian Z, Wang J, Fernald AA, Davis EM, Larson RA, White KP, Le Beau MM. Genetic pathways leading to therapy-related myeloid neoplasms. Mediterr J Hematol Infect Dis. 2011; 3:e2011019.

10. Stoddart A, Wang J, Fernald AA, Karrison T, Anastasi J, Beau MM. Cell intrinsic and extrinsic factors synergize in mice with haploinsufficiency for Tp53, and two human del(5q) genes, Egr1 and Apc. Blood. 2014.

11. Shafarenko M, Liebermann DA, Hoffman B. Egr1 abrogates the block imparted by c-Myc on terminal M1 myeloid differentiation. Blood. 2005; 106:871-878.

12. Gibbs JD, Liebermann DA, Hoffman B. Leukemia suppressor function of Egr1 is dependent on transforming oncogene. Leukemia. 2008; 22:1909-1916.

13. Gibbs JD, Liebermann DA, Hoffman B. Egr1 abrogates the E2F-1 block in terminal myeloid differentiation and suppresses leukemia. Oncogene. 2008; 27:98-106.

14. Tanaka S, Miyagi S, Sashida G, Chiba T, Yuan J, Mochizuki-Kashio M, Suzuki Y, Sugano S, Nakaseko C, Yokote K, Koseki H, Iwama A. Ezh2 augments leukemogenicity by reinforcing differentiation blockage in acute myeloid leukemia. Blood. 2012; 120:1107-1117.

15. Lund K, Adams PD, Copland M. EZH2 in normal and malignant hematopoiesis. Leukemia. 2014; 28:44-49.

16. Fu L, Huang W, Jing Y, Jiang M, Zhao Y, Shi J, Huang S, Xue X, Zhang Q, Tang J, Dou L, Wang L, Nervi C, et al. AML1-ETO triggers epigenetic activation of early growth response gene 1 , inducing apoptosis in $\mathrm{t}(8 ; 21)$ acute myeloid leukemia. Febs j. 2013.

17. Baron V, Adamson ED, Calogero A, Ragona G, Mercola D. The transcription factor Egr1 is a direct regulator of multiple tumor suppressors including TGFbeta1, PTEN, p53, and fibronectin. Cancer Gene Ther. 2006; 13:115-124.

18. Peng C, Chen Y, Yang Z, Zhang H, Osterby L, Rosmarin AG, Li S. PTEN is a tumor suppressor in CML stem cells and BCR-ABL-induced leukemias in mice. Blood. 2010; 115:626-635.

19. Zhu X, Wang L, Zhang B, Li J, Dou X, Zhao RC. TGFbeta1-induced PI3K/Akt/NF-kappaB/MMP9 signalling pathway is activated in Philadelphia chromosome-positive chronic myeloid leukaemia hemangioblasts. J Biochem. 2011; 149:405-414.

20. Wendel HG, de Stanchina E, Cepero E, Ray S, Emig M, Fridman JS, Veach DR, Bornmann WG, Clarkson B, McCombie WR, Kogan SC, Hochhaus A, Lowe SW. Loss of p53 impedes the antileukemic response to BCR-ABL inhibition. Proc Natl Acad Sci U S A. 2006; 103:74447449.

21. Takahashi N, Miura I, Saitoh K, Miura AB. Lineage involvement of stem cells bearing the philadelphia chromosome in chronic myeloid leukemia in the chronic phase as shown by a combination of fluorescence-activated cell sorting and fluorescence in situ hybridization. Blood. 1998; 92:4758-4763.

22. Kabarowski JH, Witte ON. Consequences of BCR-ABL expression within the hematopoietic stem cell in chronic myeloid leukemia. Stem Cells. 2000; 18:399-408.

23. Melo JV, Barnes DJ. Chronic myeloid leukaemia as a model of disease evolution in human cancer. Nat Rev Cancer. 2007; 7:441-453.

24. Calabretta B, Perrotti D. The biology of CML blast crisis. Blood. 2004.

25. Pierce A, Spooncer E, Wooley S, Dive C, Francis JM, Miyan J, Owen-Lynch PJ, Dexter TM, Whetton AD. BcrAbl protein tyrosine kinase activity induces a loss of p53 protein that mediates a delay in myeloid differentiation. Oncogene. 2000; 19:5487-5497.

26. Ye D, Wolff N, Li L, Zhang S, Ilaria RL Jr. STAT5 signaling is required for the efficient induction and maintenance of CML in mice. Blood. 2006; 107:4917-4925.

27. Ren R. The molecular mechanism of chronic myelogenous leukemia and its therapeutic implications: studies in a murine model. Oncogene. 2002; 21:8629-8642.

28. Wertheim JA, Miller JP, Xu L, He Y, Pear WS. The biology of chronic myelogenous leukemia:mouse models and cell 
adhesion. Oncogene. 2002; 21:8612-8628.

29. Min IM, Pietramaggiori G, Kim FS, Passegué E, Stevenson KE, Wagers AJ. The Transcription Factor EGR1 Controls Both the Proliferation and Localization of Hematopoietic Stem Cells. Cell Stem Cell. 2008; 2:380-391.

30. Joslin JM, Fernald AA, Tennant TR, Davis EM, Kogan SC, Anastasi J, Crispino JD, Le Beau MM. Haploinsufficiency of EGR1, a candidate gene in the $\operatorname{del}(5 \mathrm{q})$, leads to the development of myeloid disorders. Blood. 2007; 110:719726.

31. Stoddart A, Fernald AA, Wang J, Davis EM, Karrison T, Anastasi J, Le Beau MM. Haploinsufficiency of del(5q) genes, Egr1 and Apc, cooperate with Tp53 loss to induce acute myeloid leukemia in mice. Blood. 2014; 123:10691078.

32. Verduci L, Azzalin G, Gioiosa S, Carissimi C, Laudadio I, Fulci V, Macino G. microRNA-181a enhances cell proliferation in acute lymphoblastic leukemia by targeting EGR1. Leuk Res. 2015; 39:479-485.

33. Contreras JR, Palanichamy JK, Tran TM, Fernando TR, Rodriguez-Malave NI, Goswami N, Arboleda VA, Casero D, Rao DS. MicroRNA-146a modulates B-cell oncogenesis by regulating Egr1. Oncotarget. 2015; 6:11023-11037. https://doi.org/10.18632/oncotarget.3433.
34. Yun S, Vincelette ND, Knorr KL, Almada LL, Schneider PA, Peterson KL, Flatten KS, Dai H, Pratz KW, Hess AD, Smith BD, Karp JE, Hendrickson AE, et al. 4EBP1/ c-MYC/PUMA and NF-kappaB/EGR1/BIM pathways underlie cytotoxicity of mTOR dual inhibitors in malignant lymphoid cells. Blood. 2016; 127:2711-2722.

35. Lee SL, Sadovsky Y, Swirnoff AH, Polish JA, Goda P, Gavrilina G, Milbrandt J. Luteinizing hormone deficiency and female infertility in mice lacking the transcription factor NGFI-A (Egr1). Science. 1996; 273:1219-1221.

36. Chen Y, Sullivan C, Peng C, Shan Y, Hu Y, Li D, Li S. A tumor suppressor function of the Msr1 gene in leukemia stem cells of chronic myeloid leukemia. Blood. 2011.

37. Mukherjee K, Sha X, Magimaidas A, Maifrede S, Skorski T, Bhatia R, Hoffman B, Liebermann DA. Gadd45a deficiency accelerates BCR-ABL driven chronic myelogenous leukemia. Oncotarget. 2017. 14; 8: 10809-10821. https:// doi.org/10.18632/oncotarget.14580.

38. Magimaidas A, Madireddi P, Maifrede S, Mukherjee K, Hoffman B, Liebermann DA. Gadd45b deficiency promotes premature senescence and skin aging. Oncotarget. 2016; 7:26935-26948. https://doi.org/10.18632/oncotarget.8854. 